\title{
A METHOD FOR DESIGNING THE LONGITUDINAL POSITION OF A PORTHOLE IN A MANNED SUBMERSIBLE BASED ON THE BACK MUSCLE FATIGUE CHARACTERISTICS
}

\author{
MENGYA ZHU ${ }^{1,2}$, DENGKAI CHEN ${ }^{1,2}$, YU FAN $^{1,2}$, and JIAYAN GUO ${ }^{1,2}$ \\ ${ }^{1}$ Northwestern Polytechnical University, Xi'an, China \\ Shaanxi Engineering Laboratory for Industrial Design \\ ${ }^{2}$ Ministry of Industry and Information Technology, Xi'an, China \\ Key Laboratory
}

\begin{abstract}
Objectives: The proper porthole angle contributes to relieving the operation fatigue and improving the efficiency of oceanauts. In this study, the authors explored the effect of 3 different porthole longitudinal positions on the oceanauts' back muscles using surface electromyography (sEMG) analysis, and the characteristics of the perceived body comfort was obtained. Material and Methods: Overall, 40 healthy participants were recruited to perform tasks in a simulated cabin environment. Electromyographic (EMG) signals were recorded from the trapezius medius, lower trapezius, and erector spinal muscles for porthole angles of $-5^{\circ},-15^{\circ}$, and $+15^{\circ}$, relative to the horizontal line of sight during a 21-minute experiment. The subject comfort scores were collected at 7,14 and $21 \mathrm{~min}$. The integrated electromyogram (iEMG) and the root mean square (RMS) of EMG signals, as well as the mean power frequency (MPF), and the mean frequency (MF) were calculated. Results: The subjective scores of the $+15^{\circ}$ porthole at each stage of work are higher than those of the $-15^{\circ}$ and $-5^{\circ}$ portholes. The results of iEMG, RMS, MF and MPF all indicated that the $+15^{\circ}$ porthole design was more conducive to lowering the rate of muscle fatigue, while the $-5^{\circ}$ and $-15^{\circ}$ portholes increased the muscle fatigue rate and led to greater fatigue. It was found that the lower trapezius was more prone to fatigue than the trapezius medius and erector spinal muscles. The height, weight and body mass index of the participants were found to negatively correlate with muscles at the $+15^{\circ}$ porthole, which is highly consistent with the actual situation. Conclusions: The findings suggested that the $+15^{\circ}$ position was optimal for delaying the muscle fatigue of the participants and for improving the work efficiency of oceanauts. Int J Occup Med Environ Health. 2021;34(6):701-21
\end{abstract}

Key words:

surface electromyography, muscle fatigue, work efficiency, manned submersible, porthole position design, oceanauts

\section{INTRODUCTION}

Manned submersibles are essential tools and indispensable platforms for deep-sea scientific research and resource exploration [1]. Their main tasks include the exploration of marine geology, the investigation of submarine environments, in-depth sea exploration, high-precision topographic surveying of oceans, and the detection and capture of new materials on the seabed. The manned submersible cabin is the space where the oceanauts operate, and it is usually designed as a small and spherical hull [2]

Funding: this work was supported by the Ministry of Education of China (grant No. B13044 entitled the "111 Project," and grant No. 31020190504007 entitled "The Fundamental Research Funds for the Central Universities," grant manager: Prof. Dengkai Chen).

Received: June 15, 2020. Accepted: February 11, 2021.

Corresponding author: Dengkai Chen, Northwestern Polytechnical University, Shaanxi Engineering Laboratory for Industrial Design, Youyixi Road, Xi’an, Shaanxi 710072, China (e-mail: chendengkai@nwpu.edu.cn). 
to resist the intense underwater pressure of the deep sea. The working cabin has an average diameter of $2 \mathrm{~m}$, which can be constrained by the floor height, ceiling height, and various instruments and equipment. Furthermore, it must accommodate 3 people, including an oceanaut, who is the main manipulator, drives the manned submersible and conducts operations in the deep sea; an assistant responsible for receiving orders from the oceanaut to complete the assistance work; and a scientist who puts forward scientific research needs through the observation monitor. Thus, it is a small working space with less than $2 \mathrm{~m}^{3} /$ person [3].

At present, as manned submersibles explore greater depths, the cabin diameters continue to decrease. As a result, the area of activity per person is smaller. Due to the fact that improvements in operators' comfort help to thin out their errors and accidents [4], the research of comfort for manned submersibles is a technology trend of the future.

During the course of operation, the manned submersible cabin is a complex operating system, which includes a complex environment and complicated tasks. "Complex environment" means that the overall working space is small, and the space environment is constrained by a variety of conditions. Furthermore, the physical environment in the cabin is harsh, and the temperature, humidity, and air quality are unstable with changes in the water depth. "Complex tasks" mean that there are 12 operating systems for manned submersibles, mainly including structural systems, power systems, life support systems, submersible emergency load dumping systems, underwater acoustic communication systems, and control systems. During the operation of a submersible, an oceanaut must keep his body leaning forward to look at the porthole while planning activities, supervising the system status, operating a variety of controllers and equipment panels, and anticipating future tasks. These include autonomously operating the submersible to carry out a series of activities, such as sailing and sitting on the bottom, fine measurements and sampling, and high-definition video photography. Because of the complexity of the system, the psychological quality and the physical function of oceanauts are very important for the safe and efficient operation of the submersible.

According to the current sea test statistics, when the diving depth is $3000 \mathrm{~m}$, the operating cycle is generally 7-9 h; when the diving depth is $5000 \mathrm{~m}$, the operating cycle is generally $10-11 \mathrm{~h}$; and when the diving depth is $7000 \mathrm{~m}$, the operating cycle is up to $12 \mathrm{~h}$ or more. Oceanauts usually need to concentrate on diving for $8-10 \mathrm{~h}$ in the dark. With the advancement of technology and further exploration in the field of deep-sea navigation, the diving depth will increase, so oceanauts will work longer in high temperatures, high humidity, and small cabins. "Jiaolong," a 7000-meter sea trial experiment, is considered an example. During the "Jiaolong" 7000-meter sea trail, the mission time ranges $410-750 \mathrm{~min}$ [5]. In a 12-hour total mission time, the submersible diving time was $1 \mathrm{~h}$ and $40 \mathrm{~min}$, the cruise and subsea operation time totaled $5 \mathrm{~h}$ and $30 \mathrm{~min}$, and the floating operation time was $3 \mathrm{~h}$ and $30 \mathrm{~min}$ [6].

During the dive and ascent, the oceanauts need to observe the external environment from the porthole from time to time. During the cruise and seafloor operations, the oceanauts must maintain a forward leaning posture and continue to observe the porthole for $>5 \mathrm{~h}$. The deepsea working environment of manned submersibles requires the operator to concentrate on sensing, analyzing, and processing a large amount of visual and auditory information for a long time, which can cause oceanaut fatigue. In the course of this work, due to the extremely small movement space in the working cabin, the movement of the oceanauts is limited, and the lower limbs cannot move freely. Oceanauts also need to focus on perceiving, analyzing, and processing large amounts of visual and auditory information [7,8]. This will cause the spine and muscles to be in a prolonged high-tension state, the muscles to contract, the blood vessels to be compressed, the blood supply 
to be reduced, and the tissue ischemia, hypoxia, and anaerobic metabolism to increase, which can cause local neuromuscular fatigue or even potential disabling injuries or musculoskeletal conditions.

In fact, studies have shown that leaning forward causes not only shoulder pain but also back discomfort. Keeping the shoulder rigid over an extended period can produce shoulder pain, dizziness, headaches, and possibly even memory loss and short-term cognitive impairment, which can negatively impact on the learning ability and work efficiency [9]. Through an experimental comparison of each subject sitting in 3 sitting positions (i.e., upright, prone, and forward leaning positions) for $1 \mathrm{~h}$, the conclusion was that the sitting posture with the highest lower back discomfort after prolonged sitting was the forward leaning posture [10]. Engaging in high-precision work in such a harsh environment for a long time will cause fatigue of the oceanauts' muscles, increase the risks of performing tasks, and reduce the reliability of the oceanauts' work.

Thus, it is important to effectively improve the human reliability of oceanauts, and to create a low fatigue, congestion, and tension working environment. According to the previous study on the layout of a manned submarine cabin [3], the porthole position has the largest fatigue effect on oceanauts. Since the porthole's lateral position is fixed, the research on the longitudinal position of the portholes should be discussed thoroughly. However, little work has focused on the proper longitudinal position of the porthole. Taking deep-sea environmental research and geological exploration tasks as an example, the oceanauts must hold a manipulator while performing sampling tasks and leaning forward to look outside the front porthole, which is quite different from workers using computer screens (as shown in Figure 1). In this way, the muscle fatigue characteristics of oceanauts while working should be studied separately from workers using computer screens for prolonged times.
Traditionally, muscle fatigue has been defined as the inability of muscles to maintain a predetermined level of strength [11], which can cause changes in the surface electromyographic (sEMG) signal spectrum [12]. A common way to objectively measure muscle fatigue is by evaluating the electromyographic (EMG) signal [13].

Among the various methods for neuromuscular fatigue assessment, sEMG is the preferred method of ergonomics [14]. Before the 1980s, most studies used sEMG signal spectrum analysis to study fatigue indicators. After the 1980s, time-frequency analysis, reflection response, waveform analysis, and linear modeling were used to investigate the muscle fatigue index. Enoka and Stuart [15] used changes in the muscle activity and the maximum output force to quantify muscle fatigue. Al-Mulla et al. [16] pointed out that the characteristics of EMG signals change significantly during fatigue, and the relationship between the amplitude of the sEMG signal and the muscle force do not remain the same, so sEMG can be used to record and explain the electrical activity of active muscle fibers during contraction.

Piper [17] was one of the first researchers to use sEMG technology to track the myoelectric manifestations of muscle fatigue. Lindstrom et al. [18] linked the changes in the spectrum of the EMG recordings during the evolution of muscle fatigue to the reduction in the muscle fiber conduction velocity. He also proposed a numerical fatigue index to indicate the progression of the muscle under load to a state of being incapable of providing the required strength again [19]. Balasubramanian et al. [20] studied the effects of sEMG on the back and shoulder muscles of helicopter pilots. Haddad and Mirka [21] evaluated the impact of short-term muscle fatigue on muscle gain values. Thompson et al. [22] used multiple muscle groups to assess the fatigue and characterize the fatigue responses of nursing workers. Finally, Anand et al. [23] assessed muscle activities related to shoulder pain among the occupational ironing workers using sEMG. 
a)

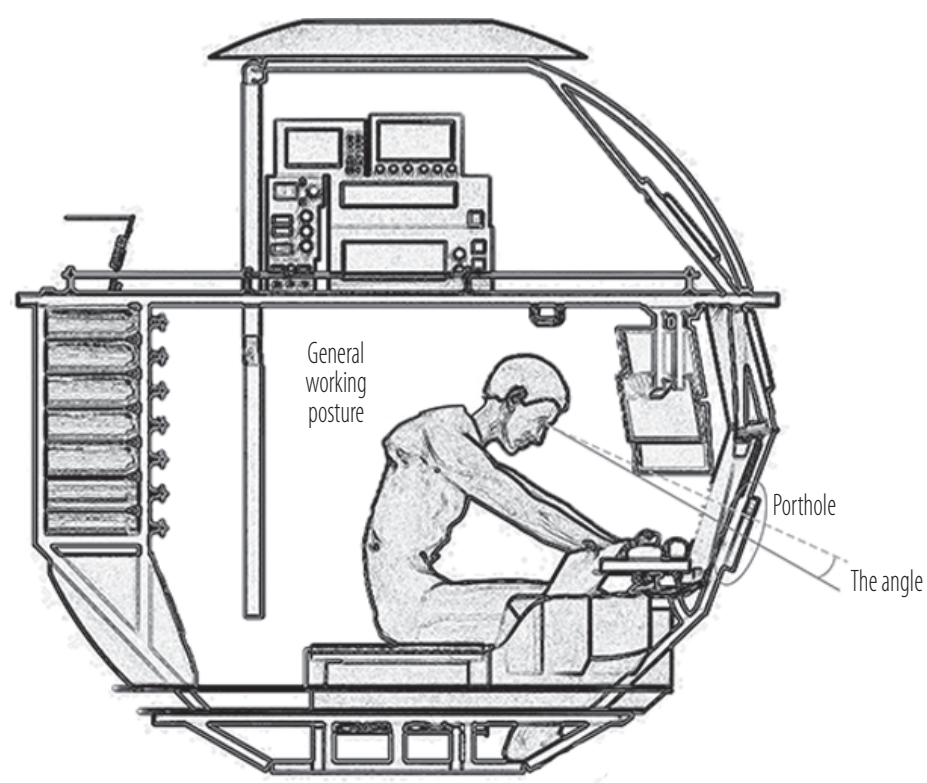

b)

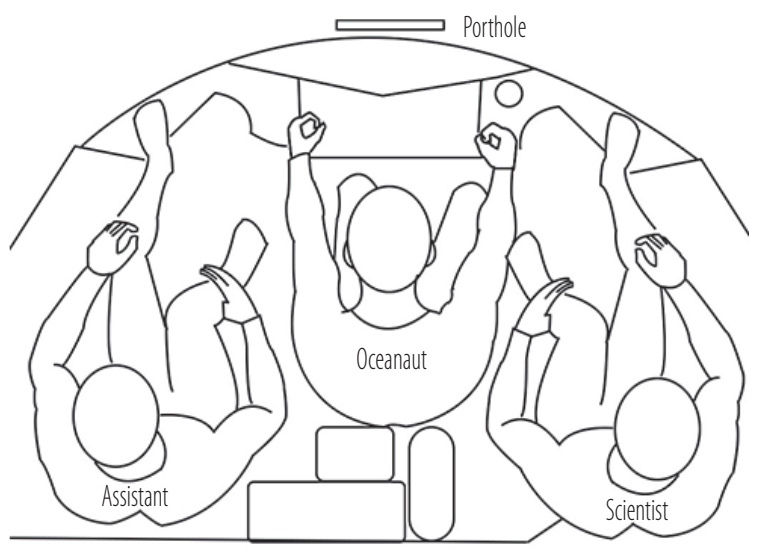

c)

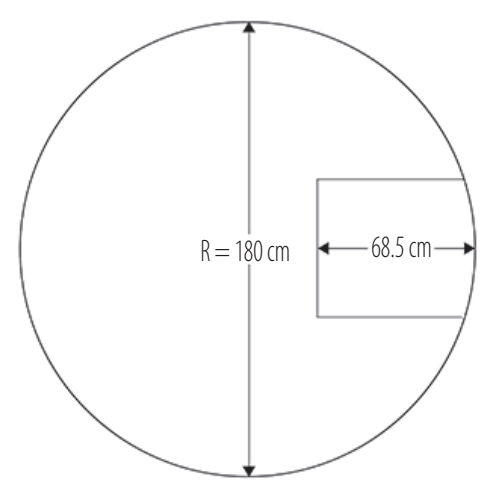

4

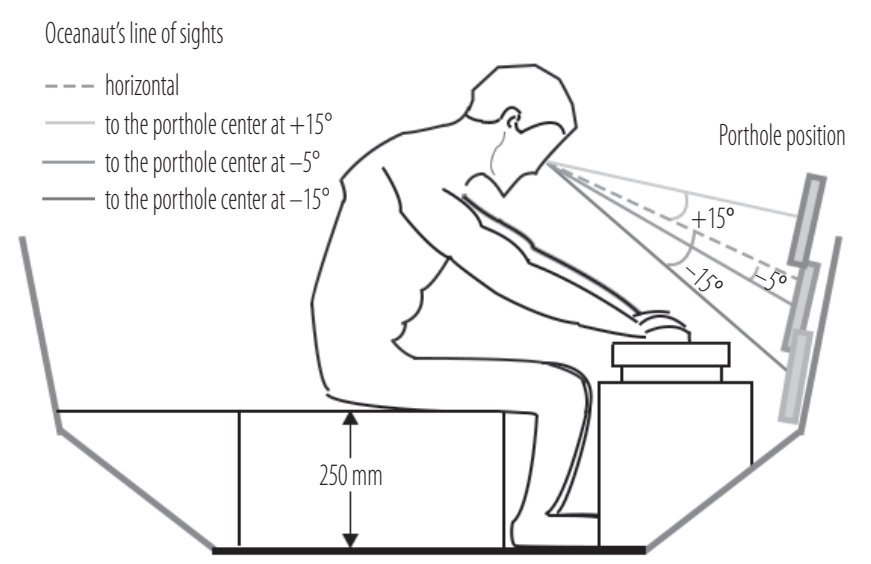

Figure 1. A scheme of oceanaut working conditions and experimental conditions: a) the actual oceanaut working status, b) a overlooking diagram in the 3-participant experimental group, c) a cross-sectional view of the floor in the 1-participant experimental group, and d) participant experimental porthole position setting in the study on healthy young people $(\mathrm{N}=40)$, conducted in the Northwestern Polytechnical University, Xi'an, China, in July-September 2019

In this paper, the authors compared the 3 most commonly designed porthole longitudinal positions in a simulated environment to investigate oceanaut muscle fatigue. To quantify muscle fatigue, they used sEMG signals to explore the fatigue states of the oceanauts' muscles while subjective scales were employed to explore the perceived discomfort of the oceanauts. This combination of subjective and objective methods can effectively improve the significance of the experimental results. Through the analysis and comparison of the experimental results, the authors obtained the muscle fatigue characteristics of the oceanauts, providing a design method for the longitudinal positioning of portholes. 


\section{MATERIAL AND METHODS}

\section{Participants}

Forty healthy young people were recruited for this study (their anthropometric values are listed in Table 1), including 30 males and 10 females. The authors ensured that they had experienced no symptoms of musculoskeletal, neck, or back pain for the past 12 months, with no history of spinal disease, and no signs of neurological dysfunction, osteoarthritis, rheumatoid arthritis, gout, kidney disease, open wounds or contusions on the buttocks, or acne. Meanwhile, all participants were informed about the study and were asked to sign a consent form before participation.

\section{Experimental design}

The authors used flexible wooden bars to construct a spherical cabin with a diameter of $2 \mathrm{~m}$ as the standard to limit the range of activities of the participants (Figure 1a). Meanwhile, they made a control panel from cardboard, which contained raised control buttons, and used a display screen with dimensions of $204.2 \times 122.2 \times 8.2 \mathrm{~mm}$ as the simulated porthole to create a working environ- ment for the oceanauts that was as real as possible. Based on the seat height and width of the "Jiaolong" manned submersible, a seat height of $250 \mathrm{~mm}$ was provided for the participants.

In this study, 2 kinds of experiments with a total of 40 groups were conducted. There were 30 groups in the first kind of experiment, and only 1 person was invited as the participant in each experimental group. In the second kind of experiment, 3 people were invited to take on the work of the oceanaut, the assistant and the scientist, respectively, in each group, just like the real manned submersible diving operations, as shown in Figure 1b. For experiments with only 1 participant, the working space of the participant was limited by fixing the placement of the legs according to the floor as the actual situation of a manned submersible. The floor, as shown in Figure 1c, was put in the cabin. The distance between the floor and the bottom of the cabin was $250 \mathrm{~mm}$, which was coincident with the height of the seat. During the experiment, the participant sat directly on the floor, and not on the seat (Figure 1d).

The sEMG changes were measured at different porthole heights when the participants in the role of oceanauts were

Table 1. The sample characteristics of the healthy young people as participants in the study on the method for designing the longitudinal position of the porthole in a manned submersible, conducted in the Northwestern Polytechnical University, Xi'an, China, in July-September 2019

\begin{tabular}{|c|c|c|c|c|c|c|c|}
\hline \multirow[b]{3}{*}{ Variable } & \multicolumn{7}{|c|}{$\begin{array}{l}\text { Participants } \\
(\mathrm{N}=40)\end{array}$} \\
\hline & & $\begin{array}{c}\text { men } \\
(\mathrm{N}=26)\end{array}$ & & & $\begin{array}{c}\text { women } \\
(\mathrm{N}=14)\end{array}$ & & \multirow[b]{2}{*}{ total } \\
\hline & $\begin{array}{l}\text { in } 30 \text { one- } \\
\text { participant } \\
\text { experimental } \\
\text { sets } \\
(\mathrm{N}=20)\end{array}$ & $\begin{array}{l}\text { in } 10 \text { three- } \\
\text { participant } \\
\text { experimental } \\
\text { sets } \\
(\mathrm{N}=6)\end{array}$ & in all sets & $\begin{array}{l}\text { in } 30 \text { one- } \\
\text { participant } \\
\text { experimental } \\
\text { sets } \\
(\mathrm{N}=10)\end{array}$ & $\begin{array}{c}\text { in } 10 \text { three- } \\
\text { participant } \\
\text { experimental } \\
\text { sets } \\
(\mathrm{N}=4)\end{array}$ & in all sets & \\
\hline Age [years] $(\mathrm{M} \pm \mathrm{SD})$ & $23.6 \pm 6.61$ & $21.4 \pm 4.46$ & $23.09 \pm 4.51$ & $20.4 \pm 4.7$ & $19.3 \pm 5.25$ & $20.09 \pm 5.36$ & $22.04 \pm 5.90$ \\
\hline Height $[\mathrm{cm}](\mathrm{M} \pm \mathrm{SD})$ & $167 \pm 12.39$ & $170 \pm 12.68$ & $167.69 \pm 13.20$ & $161 \pm 9.55$ & $164 \pm 9.10$ & $161.86 \pm 11.36$ & $165.65 \pm 12.61$ \\
\hline Weight $[\mathrm{kg}](\mathrm{M} \pm \mathrm{SD})$ & $65 \pm 6.88$ & $60 \pm 10.76$ & $63.85 \pm 8.74$ & $53 \pm 7.24$ & $52 \pm 7.02$ & $52.71 \pm 8.54$ & $59.95 \pm 8.94$ \\
\hline $\mathrm{BMI}\left[\mathrm{kg} / \mathrm{m}^{2}\right](\mathrm{M} \pm \mathrm{SD})$ & $23.3 \pm 2.80$ & $20.8 \pm 6.32$ & $22.72 \pm 3.46$ & $24.1 \pm 7.89$ & $21.8 \pm 2.72$ & $23.44 \pm 3.00$ & $22.975 \pm 3.12$ \\
\hline
\end{tabular}


in a prescribed forward posture. The authors selected the most commonly designed longitudinal positions, which corresponded to the angles of $-5^{\circ},-15^{\circ}$, and $+15^{\circ}$ between the participants' horizontal line of sight and the porthole center; for simplicity, they used the porthole angle directly in the following paper, as shown in Figure 1d. The sEMG signals of the participants were recorded from the trapezius medius, lower trapezius, and erector spinal muscles for $21 \mathrm{~min}$, and the position of the electrodes that collect the sEMG signals are $50 \%$ between the medial border of the scapula and the spine, at the level of T3, two-third on the line from the trigonum spinae to the eighth thoracic vertebra and 2-finger width laterally to the spinous process of L1, respectively, as shown in Figure 2, in which $\times$ was used for the positive electrode and for the positioning electrode.

\section{Experimental procedure}

After informing the participants of the purpose of the experiment, the authorsinstructed them on how to use the subjective scale to evaluate personal comfort. They collected the maximum voluntary contraction (MVC) for the participants in advance to normalize the sEMG data. In the collection process, the participants stood on the ground, and the elastic band was wrapped around the soles of their feet and tightened at both ends manually. They pulled to their maximum voluntary capability vertically up on the elastic band, and maximum force was applied manually, and both legs applied force in the opposite direction for a 30-second muscle fatigue test, as shown in Figure 2b. The EMG signals were obtained during the MVC.

The experiments were divided into 3 parts, as shown in Figure 2. The angles between the porthole and the participants' horizontal line of sight in each part were $-15^{\circ},+15^{\circ}$, and $-5^{\circ}$. To avoid the effect of the test sequence on the fatigue degree of the participants, experiments were conducted in 6 different orders for each participant, which is shown in Figure 2c. During each part of the 21-minute experiment, the ocean pictures ( 1 of them as shown in Figure $2 d$ ) were displayed on the screen randomly. The oceanaut was required to lean forward to observe the display screen, and the myoelectric fatigue signals of the participants were recorded in real time. Moreover, the subjective scale scores were recorded at 7, 14, and $21 \mathrm{~min}$. After each part of the experiment, the participant returned to the initial muscle state after relaxing for $10 \mathrm{~min}$.

The subjective scale used 7 comfort level scores

- level 0: extremely high discomfort,

- level 1: very high discomfort,

- level 2: high discomfort,

- level 3: moderate discomfort,

- level 4: low discomfort,

- level 5: light discomfort,

- level 6: no discomfort.

In this study, the time-frequency domain analysis of the trapezius medius, the lower trapezius, and the erector spinal EMG signals was performed to investigate the effect of each porthole angle on the muscle fatigue of the participants.

\section{Analysis}

The analysis of the sEMG data typically focuses on time and frequency analysis. The approach employed by the authors is based on the well-known fact that EMG signals are compressed in the time-frequency domain during sustained muscle contraction [24]. The integrated electromyogram (iEMG) is the sum of the area under the curve of the obtained EMG signals after rectification and filtering in a given time unit, which can reflect the change in the EMG signal with time [25]. Usually, the larger the amplitude is, the more severe the fatigue becomes, and this is a crucial time-domain index for evaluating muscle fatigue. Muscle fatigue is related to the compression of the power spectral density (PSD) of the sEMG towards lower frequency [26]. Based on the PSD estimation, the mean power frequency (MPF) and the mean frequency (MF) of the sEMG could be computed as shown in equations (1) and (2), respectively [27]. 
a)
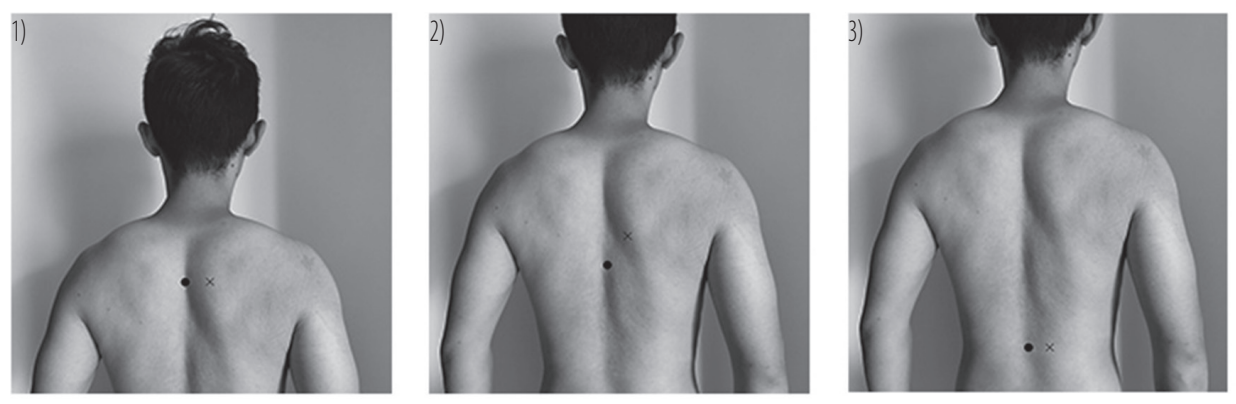

b)

Experiment preparation

1) communicate the experiment purpose

2) collect MVC

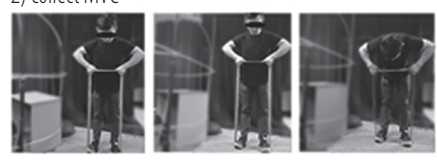

3) explain the subjective scales

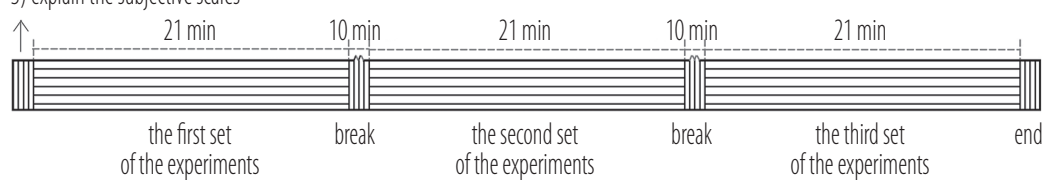

c)

Experimental proces design

\begin{tabular}{llll}
\hline 1 & $-15^{\circ}$ angle & $-5^{\circ}$ angle & $+15^{\circ}$ angle \\
2 & $-15^{\circ}$ angle & $+15^{\circ}$ angle & $-5^{\circ}$ angle \\
3 & $-5^{\circ}$ angle & $-15^{\circ}$ angle & $+15^{\circ}$ angle \\
4 & $-5^{\circ}$ angle & $+15^{\circ}$ angle & $-15^{\circ}$ angle \\
5 & $+15^{\circ}$ angle & $-5^{\circ}$ angle & $-15^{\circ}$ angle \\
6 & $+15^{\circ}$ angle & $-15^{\circ}$ angle & $-5^{\circ}$ angle \\
\hline
\end{tabular}

d)

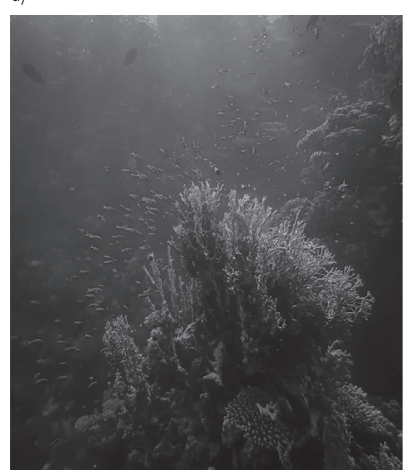

Figure 2. Experimental design: a) the position of the electrodes that collect the surface electromyography (sEMG) signals 1) the trapezius medius, 2) the lower trapezius 3) the erector spinal muscle, b) the experimental timeline, c) the different orders of experimental process, and d) an example of ocean pictures, the Northwestern Polytechnical University, Xi'an, China, in July-September 2019 
De Luca [28] showed that the amplitude and power of an EMG signal increased during fatigue, and the MF decreased. Kroghlund and Jorgensen [29] found that as the degree of fatigue increased, the root mean square (RMS) value also increased. Finally, Balasubramanian and Jayaraman [30] studied the muscle activity during aerobic exercise in athletes with and without lower back pain and determined that the RMS of the sEMG signal was the most reliable parameter in the time domain. Therefore, the muscle fatigue condition was determined in this study by analyzing the iEMG, RMS, and MF of the sEMG signal.

$$
\begin{gathered}
\text { MPF }=\frac{\int_{0}^{f_{0}} f P(f) d f}{\int_{0}^{f_{0}} P(f) d f} \\
M F=\frac{1}{2} \int_{0}^{\infty} P(f) d f
\end{gathered}
$$

where:

$\mathrm{f}$ - the frequency of sEMG signals,

$\mathrm{P}$ - the power spectral density,

$\mathrm{f}_{0}$ - the highest frequency.

Since the whole experiment lasted $21 \mathrm{~min}$, the authors divided it into 3 stages: an early stage of the task, a middle stage of the task and a later stage of task, each of which lasting $7 \mathrm{~min}$, to analysis the sEMG signals.

\section{RESULTS}

In this study, the initial EMG signal was first subjected to bias correction, filtering, and a window RMS calculation of $20 \mathrm{~ms}$.

\section{Integrated electromyogram analysis}

Based on the sEMG signal data derived from each display angle for the 21-minute experiment (a sample rate of $1000 \mathrm{~Hz}$ ), the corresponding average iEMG values of muscles of each participant at each angle/min were calculated. Meanwhile, the values in the 3 work stages of men and women, 1-participant experiment and 3-participant experiment were shown in Table 2.

The authors performed a 1-way ANOVA paired test and post-hoc multiple tests on the iEMG of the 4 groups divided as follows: men in 30 one-participant experimental sets, men in 10 three-participant experimental sets, women in 30 one-participant experimental sets, and women in 10 three-participant experimental sets. It was found that the $\mathrm{iEMG}$ values of the erector spines were significantly different from the trapezius muscles at all porthole angles during the whole course of work, and the iEMG value of the erector spinal muscle was significantly higher than the others. At the early stage of work, there was no obvious difference among the 3 muscles at different angles. However, in the middle of the mission, the $\mathrm{EMG}$ values of the lower trapezius and erector spinal muscles were both quite different between the $+15^{\circ}$ and $-15^{\circ}$ portholes, as well as in the end of the work, the erector spinal muscle was quite more fatigued than the trapezius medius. The fatigue of the lower trapezius muscle at $+15^{\circ}$ was significantly lower than at $-15^{\circ}$ and $-5^{\circ}$ in the middle stage of work, while the erector spinal muscle at $-15^{\circ}$ porthole was obviously more fatigued than at $-5^{\circ}$ and $+15^{\circ}$, as shown in Figure 3 . The authors also analyzed the relationship between the iEMG and the work stage. It can obviously be seen that the trapezius muscles would be more fatigued at $-5^{\circ}$ in the middle and later stages of work than at the beginning of work, while the erector spinal muscle was significantly fatigued in the later stage of the task than in the early stage, both at $-5^{\circ}$ and $-15^{\circ}$. However, none of the 3 muscles changed significantly over time at $+15^{\circ}$. According to the average $i E M G$ value/min, the correlation analysis between time and $\mathrm{E} M \mathrm{GG}$ values was conducted, and the results of the correlation coefficient were shown in Table 3 . The iEMG value at $-15^{\circ}$ was positively correlated with time in the lower trapezius and the erector spinal muscles, both in the middle and later stages of work, while 


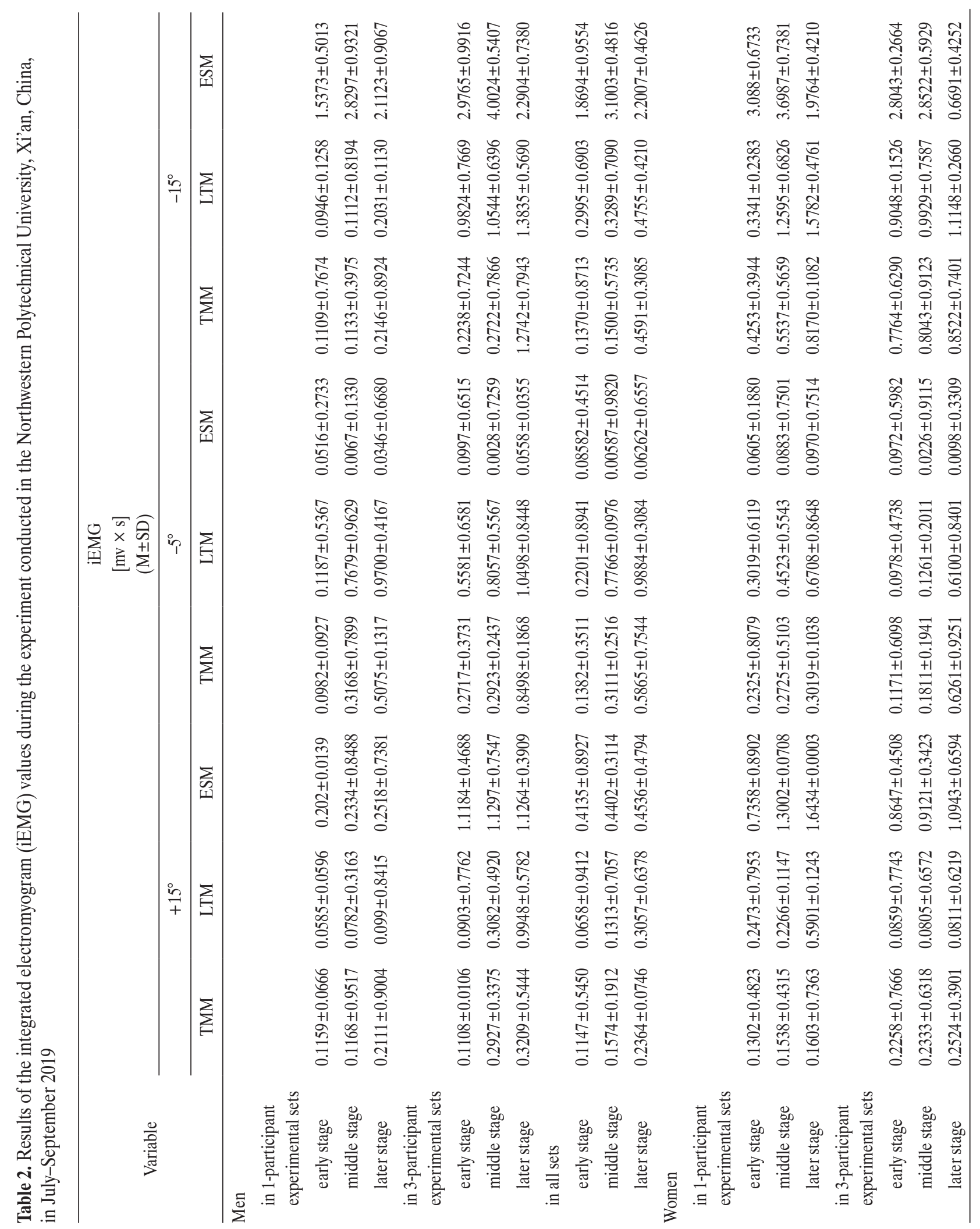




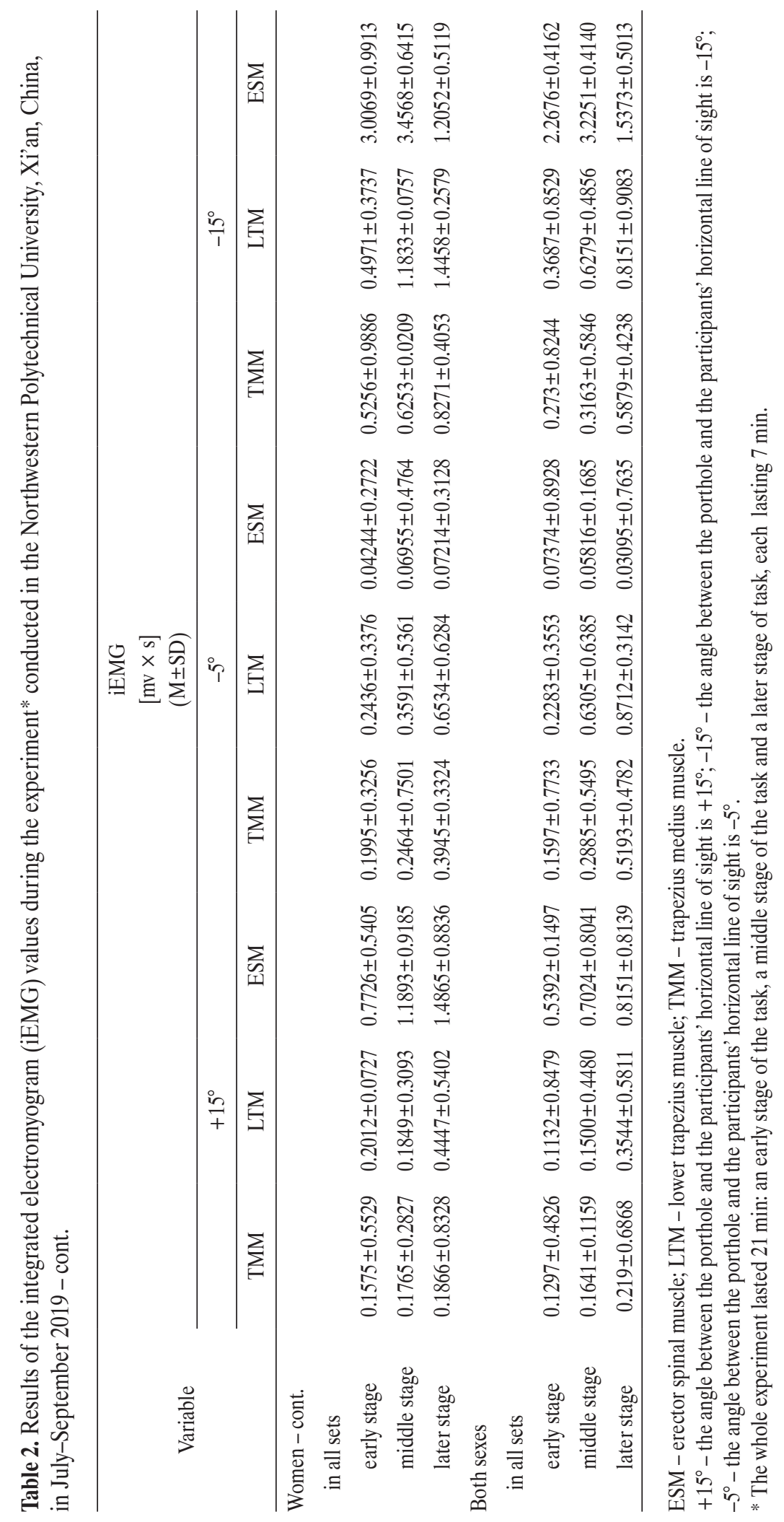



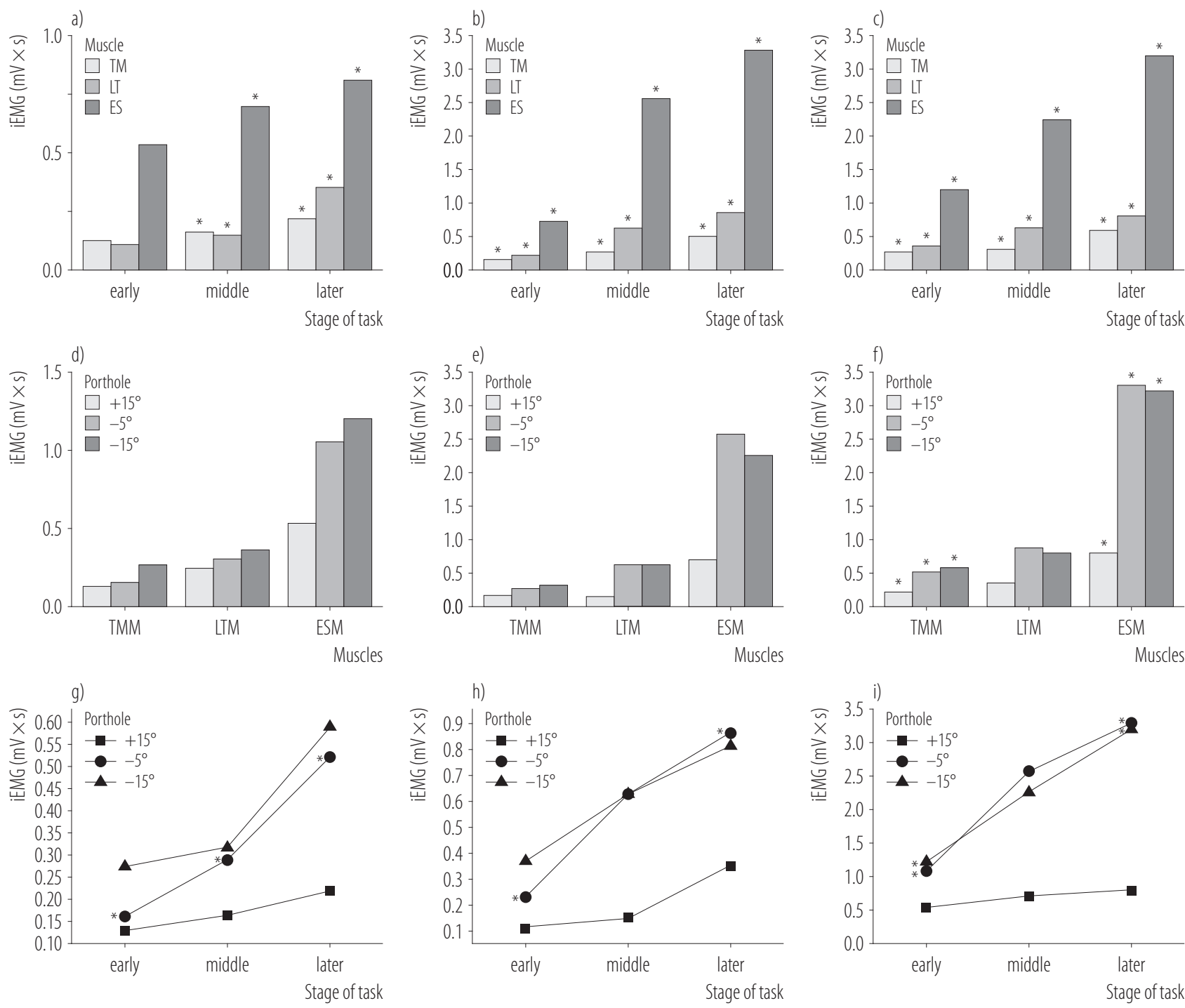

* Significant difference $(\mathrm{p}<0.05)$.

Figure 3. The weighted average integrated electromyogram (iEMG) values of 3 muscles in all experimental sets: a) at the $+15^{\circ}$ porthole, b) at the $-5^{\circ}$ porthole, c) at the $-15^{\circ}$ porthole, d) during the early stage of work, e) during the middle stage of work, f) during the later stage of work, g) of the trapezius medius (TM) muscle, h) of the lower trapezius (LT) muscle, and i) of the erector spinal (ES) muscle, during the experiment conducted on healthy young people ( $\mathrm{N}=40)$, in the Northwestern Polytechnical University, Xi'an, China, in July-September 2019

the iEMG of all muscles were not significantly correlated with time at the $+15^{\circ}$ porthole. That is, the muscles would be more fatigued at $-15^{\circ}$ porthole than at $+15^{\circ}$ over time.

\section{Normalized RMS analysis}

Based on the data derived from each display angle for the 21-minute experiment (a sample rate of $1000 \mathrm{~Hz}$ ), the corresponding average RMS of muscles at each angle in the 3 work stages of each participant were calculated. The participants were divided into 4 groups to compare the characteristic of RMS, and the average RMS values of each group are shown in Table 4. The RMS value obtained during the MVC (rms_MVC) of each muscle was also computed as follows: for male participants in the experiment, 
Table 3. Results of the correlation analysis between the stage and integrated electromyogram (iEMG) values during the experiment conducted in the Northwestern Polytechnical University, Xi'an, China, in July-September 2019

\begin{tabular}{lccccccccc}
\hline \multirow{2}{*}{\multicolumn{1}{c}{ Stage }} & \multicolumn{9}{c}{ Correlation coefficient $^{\mathrm{a}}$} \\
\cline { 2 - 10 } & \multicolumn{7}{c}{$+15^{\circ}$} & \multicolumn{7}{c}{$-5^{\circ}$} & \multicolumn{3}{c}{$-15^{\circ}$} \\
\cline { 2 - 10 } & TMM & LTM & ESM & TMM & LTM & ESM & TMM & LTM & ESM \\
\hline Early stage & -0.140 & -0.047 & 0.331 & 0.319 & 0.511 & 0.432 & $0.768^{*}$ & 0.556 & 0.382 \\
Middle stage & 0.575 & 0.520 & 0.353 & 0.314 & 0.724 & 0.422 & 0.560 & $0.906^{* *}$ & $0.823^{*}$ \\
Later stage & 0.600 & 0.477 & 0.712 & 0.389 & 0.607 & 0.506 & $0.846^{*}$ & $0.917^{* *}$ & $0.926^{* *}$ \\
\hline
\end{tabular}

Abbreviations and explanations as in Table 2.

a Pearson's correlation analysis.

* Correlation is significant at the 0.05 level difference (2-tailed); ${ }^{* *}$ Correlation is significant at the 0.01 level difference (2-tailed).

it was 0.63423 in the trapezius muscle, 0.8241 in the lower trapezius muscle, and 0.9005 in the erector spinal muscle; and for female participants, the average rms_MVC values were $0.69421,0.8993$, and 0.9572 for the trapezius muscle, the lower trapezius muscle, and the erector spinal muscle, respectively. The RMS values were normalized according to the rms_MVC obtained during the MVCs in equation (3).

$$
\mathrm{NRMS}=\frac{\mathrm{RMS}}{\text { rms_EMG }} \times 100 \%
$$

where:

NRMS - the normalized RMS,

rms_MVC - the RMS value obtained during the MVC, RMS - the RMS value in the experiment.

The authors performed a 1-way ANOVA pairing test and multiple post-hoc tests on the RMS signals at different angles of the same muscle according to the NRMS results shown in Table 4. There was a significant difference between the RMS values of the trapezius medius and erector spinal muscles at $-5^{\circ}(p<0.05)$ in the middle and later stages of work, while there was no significant difference in fatigue between the 3 muscles at $+15^{\circ}$ and $-15^{\circ}$ portholes. At the later stage of work, significant differences were observed in the trapezius medius muscle at $+15^{\circ}$ and $-15^{\circ}$, as well as in the erector spinal muscle at $+15^{\circ}$ and $-15^{\circ}$, as shown in Figure 4 .
A paired-samples t-test was also used to analyze the difference between men and women, 3-participant experimental sets and 1-participant experimental sets during the whole work, as listed in Table 5. A certain significant difference was found between men in the 3-participant sets and 1-participant sets, while the difference between women in different experimental population settings was not so evident. Compared with the 3-participant experimental group, the difference in the NRMS values of male and female participants was more obvious under the conditions of the 1-participant experimental group, especially at the $-15^{\circ}$ porthole angle.

\section{The MF and MPF analysis}

Based on the data derived after the 21-minute experiment (a sampling rate of $1000 \mathrm{~Hz}$ ), the authors calculated the MFs and MPFs of the 3 muscles of each participant. The participants were divided into 4 groups to analyze changes in muscle fatigue as shown in Tables 6-8, and the average values of MFs and MPFs in all experimental sets were shown in Figure 5.

The correlation between the MF and the participants' attributes was explored, and an obvious negative correlation was found between the body mass index (BMI) and the MF values of the trapezius medius in the $+15^{\circ}$ porthole at the early $(\mathrm{r}=-0.985, \mathrm{p}=0.01)$ and middle stages $(r=-0.846, p=0.05)$, as well as in the $-5^{\circ}$ porthole 


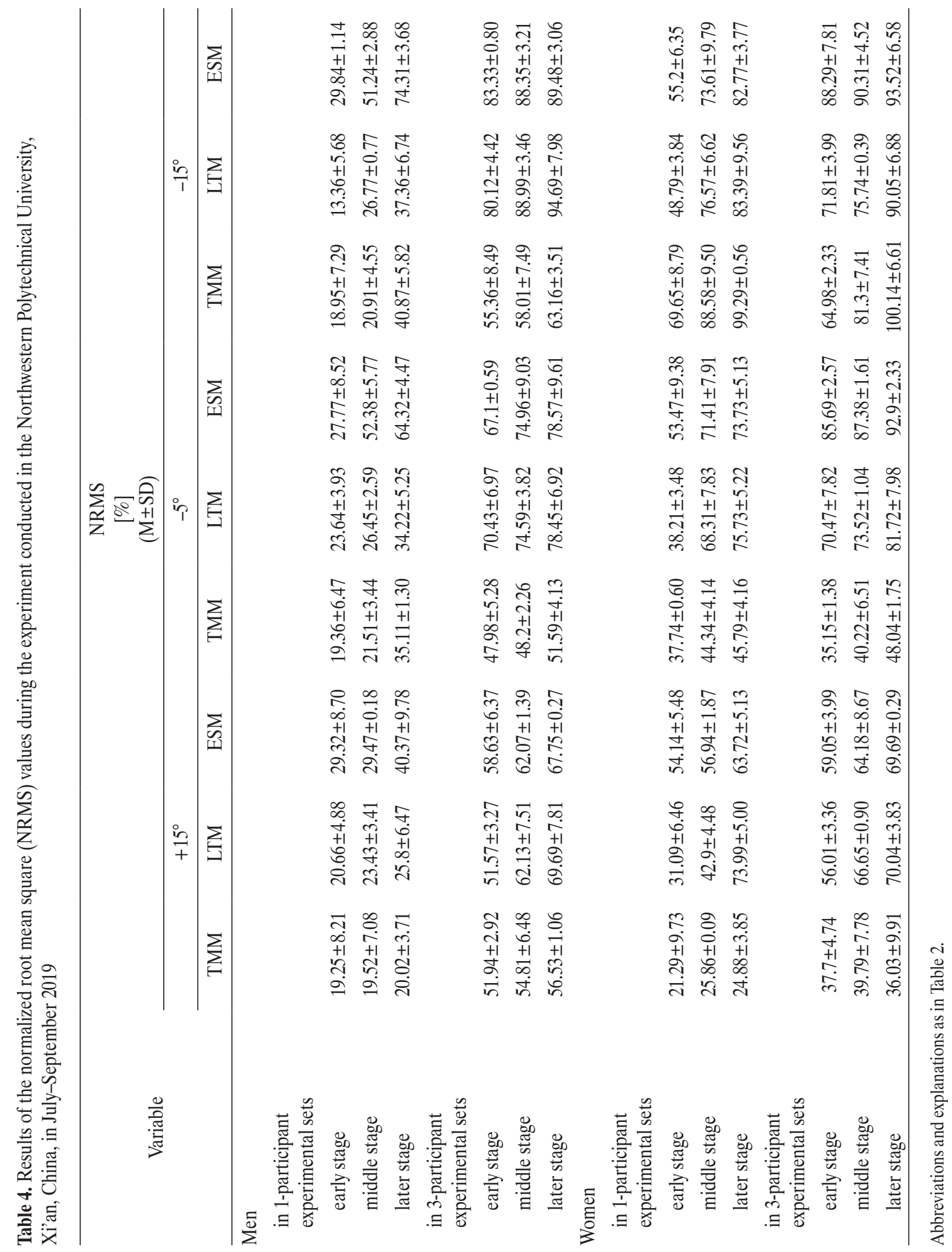



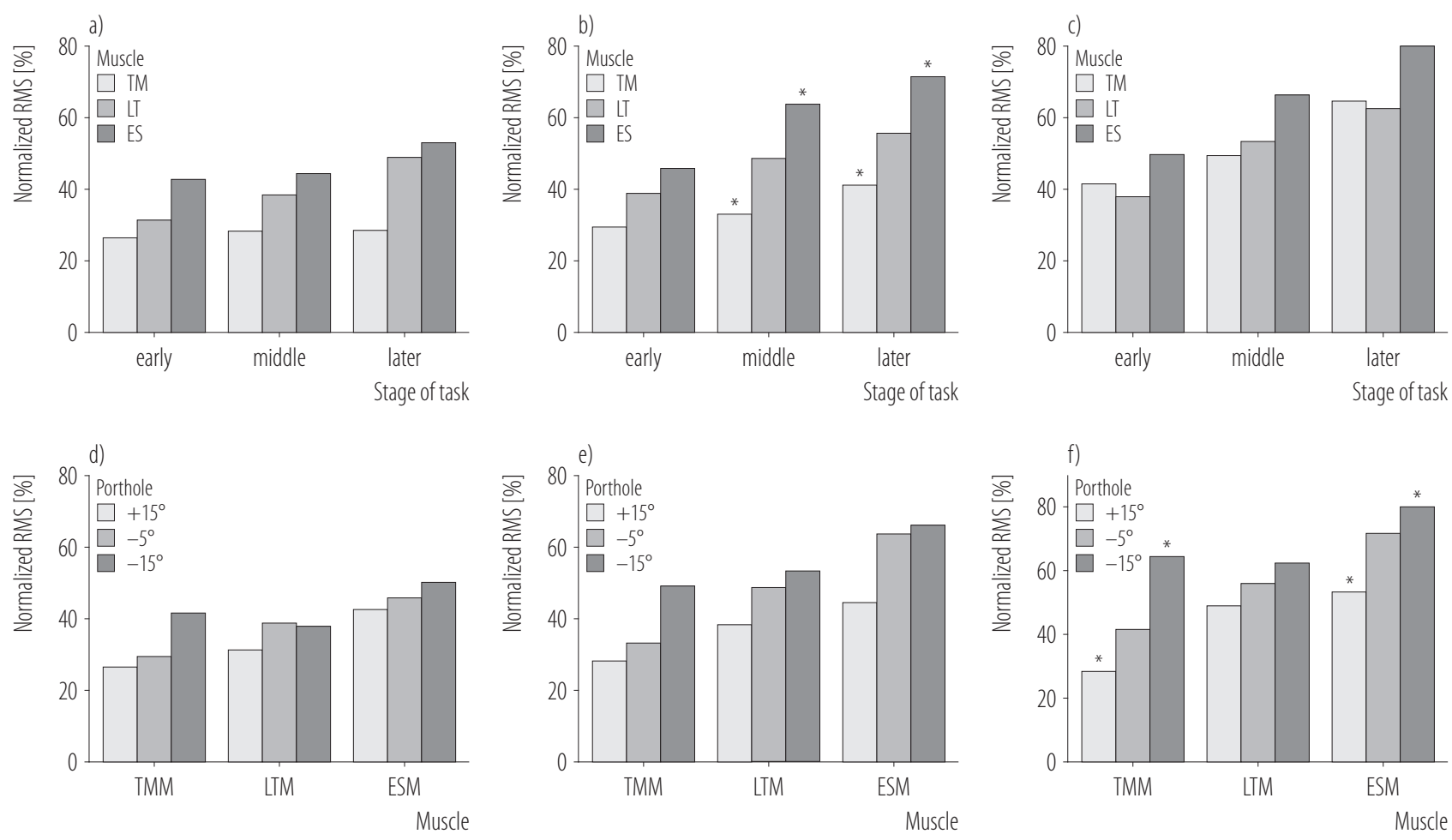

ES - erector spinal, LT - lower trapezius, TM - trapezius medius.

* Significant difference $(\mathrm{p}<0.05)$.

Figure 4. The average root mean square (RMS) values of 3 muscles from the time-series data at the portholes: a) $\left.+15^{\circ}, b\right)-5^{\circ}$, c) $-15^{\circ}$, during d) the early stage of work , e) the middle stage of work and f) the later stage of work, during the experiment conducted on healthy young people $(\mathrm{N}=40)$, in the Northwestern Polytechnical University, X'an, China, in July-September 2019

Table 5. Correlation analysis in the normalized root mean square (NRMS) values during the experiment conducted in the Northwestern Polytechnical University, Xi'an, China, in July-September 2019

\begin{tabular}{|c|c|c|c|c|c|c|c|c|c|}
\hline \multirow{3}{*}{ Variable } & \multicolumn{9}{|c|}{ Correlation coefficient $\mathrm{t}^{\mathrm{a}}$} \\
\hline & \multicolumn{3}{|c|}{$+15^{\circ}$} & \multicolumn{3}{|c|}{$-5^{\circ}$} & \multicolumn{3}{|c|}{$-15^{\circ}$} \\
\hline & TMM & LTM & ESM & TMM & LTM & ESM & TMM & LTM & ESM \\
\hline $\begin{array}{l}\text { Men in 3-participant experimental sets } \\
\text { and 1-participant sets }\end{array}$ & $0.001^{* *}$ & $0.01^{* *}$ & $0.003^{* *}$ & $0.024^{*}$ & $0.001^{* *}$ & 0.075 & $0.022^{*}$ & $0.002^{* *}$ & 0.086 \\
\hline $\begin{array}{l}\text { Women in 3-participant experimental sets } \\
\text { and 1-participant experimental sets }\end{array}$ & $0.012^{*}$ & 0.255 & $0.012^{*}$ & 0.520 & 0.245 & $0.046^{*}$ & 0.263 & 0.305 & 0.094 \\
\hline $\begin{array}{l}\text { Men and women in 1-participant } \\
\text { experimental sets }\end{array}$ & 0.073 & 0.150 & $0.002^{* *}$ & $0.040^{*}$ & 0.069 & 0.062 & $0.007^{* *}$ & $0.01^{* *}$ & 0.069 \\
\hline $\begin{array}{l}\text { Men and women in 3-participant } \\
\text { experimental sets }\end{array}$ & $0.014^{*}$ & 0.153 & 0.109 & 0.094 & 0.624 & $0.014^{*}$ & 0.098 & 0.073 & 0.054 \\
\hline
\end{tabular}

Abbreviations and explanations as in Table 2.

${ }^{a}$ Paired-samples t-test

$* \mathrm{p}<0.05 ; * * \mathrm{p}<0.01$. 


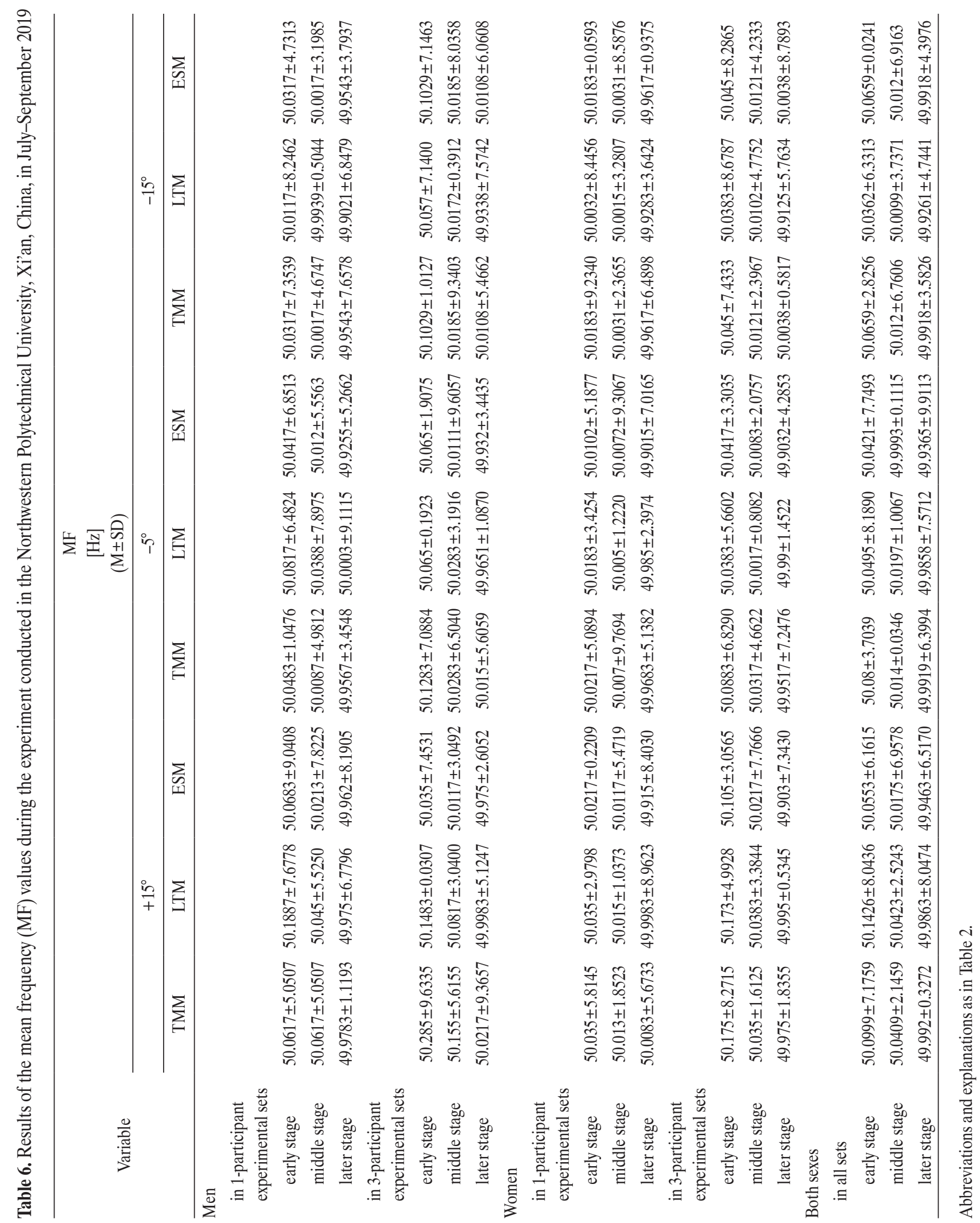




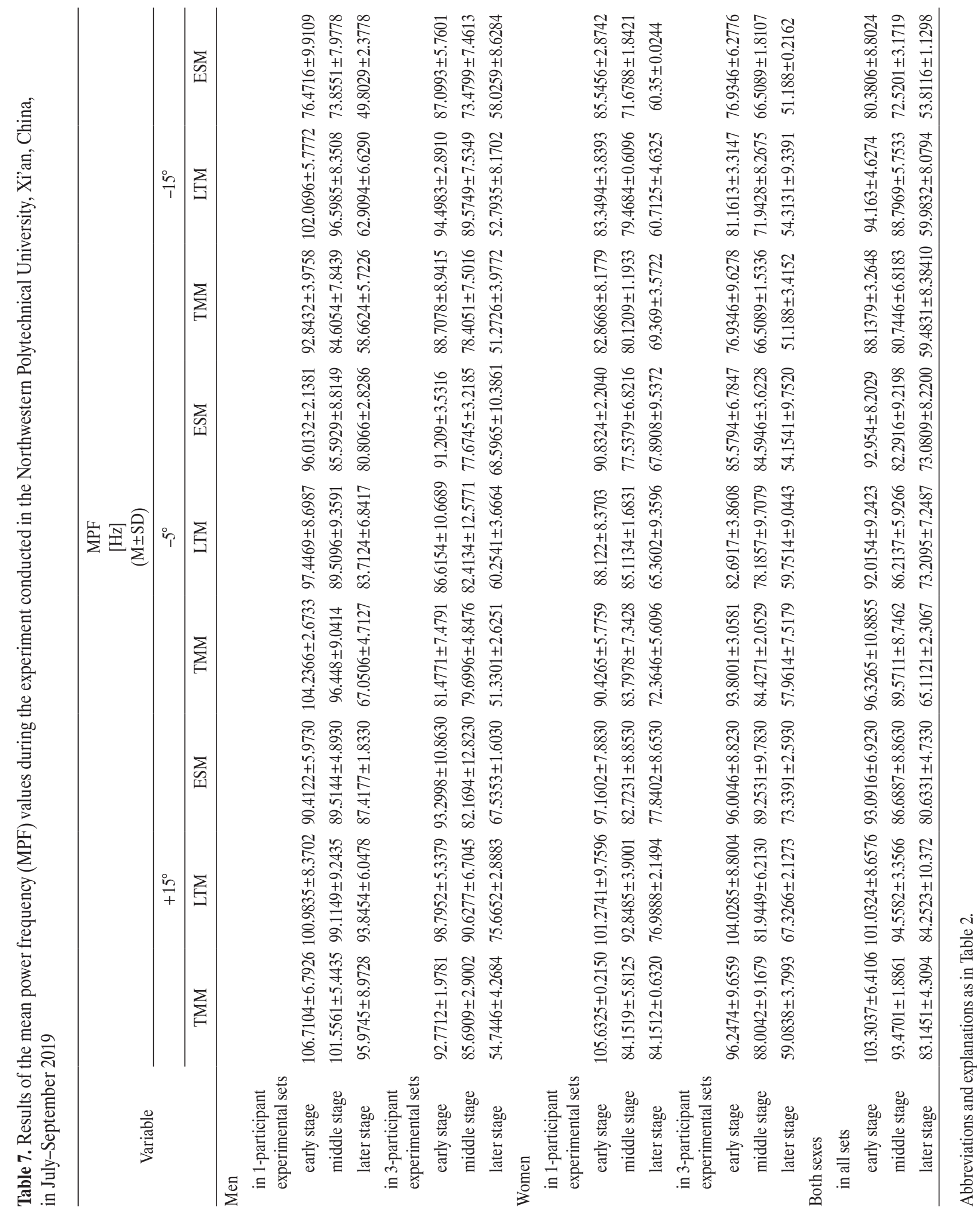


Table 8. Results of the correlation analysis of the mean power frequency (MPF) values between muscles at different porthole angles during the experiment conducted in the Northwestern Polytechnical University, Xi'an, China, in July-September 2019

\begin{tabular}{|c|c|c|c|c|c|c|c|c|c|}
\hline \multirow{3}{*}{ Variable } & \multicolumn{9}{|c|}{ Correlation coefficient ${ }^{\mathrm{a}}$} \\
\hline & \multicolumn{3}{|c|}{$+15^{\circ}$} & \multicolumn{3}{|c|}{$-5^{\circ}$} & \multicolumn{3}{|c|}{$-15^{\circ}$} \\
\hline & TMM & LTM & ESM & TMM & LTM & ESM & TMM & LTM & ESM \\
\hline \multicolumn{10}{|l|}{$+15^{\circ}$} \\
\hline TMM & - & 0.9930 & $1^{* *}$ & 0.9550 & 0.9790 & $0.998 * *$ & 0.9670 & 0.9350 & 0.9760 \\
\hline LTM & 0.9930 & - & 0.9890 & 0.9830 & 0.9960 & 0.9850 & 0.9900 & 0.9700 & 0.9950 \\
\hline ESM & $1^{* *}$ & 0.9890 & - & 0.9450 & 0.9730 & 1.0000 & 0.9590 & 0.9240 & 0.9700 \\
\hline \multicolumn{10}{|l|}{$-5^{\circ}$} \\
\hline TMM & 0.9550 & 0.9830 & 0.9450 & - & 0.9950 & 0.9360 & $0.999 * *$ & $0.998^{* *}$ & 0.9960 \\
\hline LTM & 0.9790 & 0.9960 & 0.9730 & 0.9950 & - & 0.9660 & $0.998^{* *}$ & 0.9870 & $1^{* *}$ \\
\hline ESM & $0.998^{* *}$ & 0.9850 & $1^{* *}$ & 0.9360 & 0.9660 & - & 0.9510 & 0.9130 & 0.9630 \\
\hline \multicolumn{10}{|l|}{$-15^{\circ}$} \\
\hline TMM & 0.9670 & 0.9900 & 0.9590 & $0.999 * *$ & $0.998^{* *}$ & 0.9510 & - & 0.9950 & $0.999 * *$ \\
\hline LTM & 0.9350 & 0.9700 & 0.9240 & $0.998^{* *}$ & 0.9870 & 0.9130 & 0.9950 & - & 0.9890 \\
\hline ESM & 0.9760 & 0.9950 & 0.9700 & 0.9960 & $1^{* *}$ & 0.9630 & $0.999 * *$ & 0.9890 & - \\
\hline
\end{tabular}

Abbreviations and explanations as in Table 2.

a Pearson's correlation analysis.

* Correlation is significant at the 0.05 level difference (2-tailed); ** Correlation is significant at the 0.01 level difference (2-tailed).

( $\mathrm{r}=-0.992, \mathrm{p}=0.01$ and $\mathrm{r}=0.911, \mathrm{p}=0.05$, respectively). In the $-15^{\circ}$ porthole, BMI was found to correlate with the MF values of the lower trapezius at the early $(r=0.996$, $\mathrm{p}=0.01)$ and middle stages $(\mathrm{r}=0.861, \mathrm{p}=0.05)$.

The correlation of each muscle in the MPF values was compared, and so was Pearson's correlation, as indicated in Table 8. It can be noted that a strong correlation exists among all 3 muscles at all angles of the porthole, with special reference to the $-15^{\circ}$ porthole at which the lower trapezius is strongly associated with the erector spinal muscle, while it also had a significant correlation with the trapezius muscles at $-5^{\circ}$.

\section{Subjective scale analysis}

The average subjective scores in all body regions were calculated as listed in Table 9, and a correlation between time and subject scores was applied to analyze the difference of each porthole angle. It was found that the comfort feelings of all regions in the later stage were lower than in the early and middle stages, as shown in Table 9, while subjective scores at the $-15^{\circ}$ porthole were significantly lower than for other porthole angles.

\section{DISCUSSION}

\section{Discussion on iEMG and RMS}

The authors firstly analyzed the time domain parameter such as iEMG and the RMS values of each muscle at different experiment porthole angle. It can be seen that the iEMG and RMS values of muscles at $+15^{\circ}$ are relatively lower than those at other porthole angles. The 1-way ANOVA test results of $\mathrm{EMG}$ and RMS both showed that either muscle did not show obvious fatigue changes at $+15^{\circ}$ and $-5^{\circ}$ as the task was going on, while the parameter value of the muscles increased significantly at $-15^{\circ}$. So, it appears 

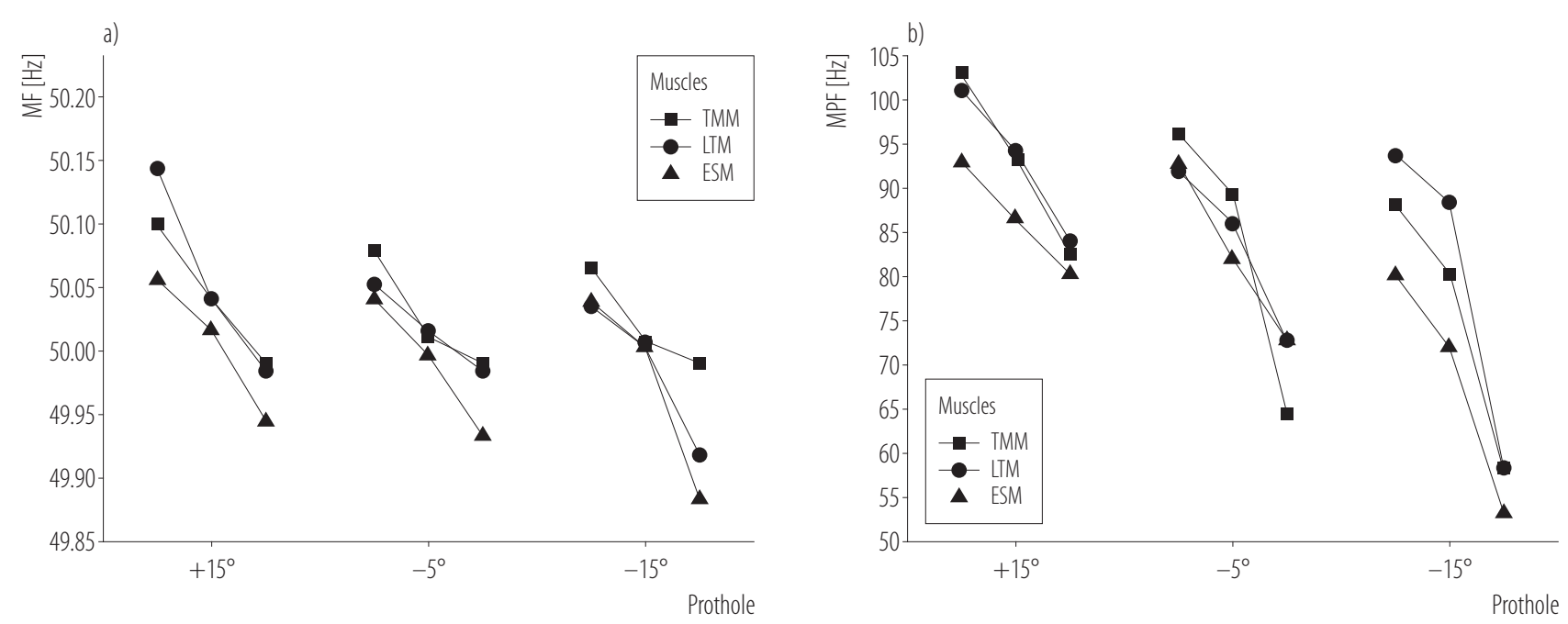

Figure 5. The results of a) mean frequency (MF), and b) mean power frequency (MPF) values of 3 muscles during all stages of work, during the experiment conducted on healthy young people $(\mathrm{N}=40)$, in the Northwestern Polytechnical University, Xi'an, China, in July-September 2019

that the muscle fatigue accumulation at $+15^{\circ}$ and $-5^{\circ}$ was slower than that at the $-15^{\circ}$ porthole. Meanwhile, the fatigue rate at $-5^{\circ}$ was more obvious than that at $+15^{\circ}$.

It is evident from the results that the fatigue of the erector spinal muscle is more pronounced that that of the trapezius muscles at all angles, according to the iEMG and RMS values of all sets listed in Tables 2 and 3. Considering the actual situation obtained in the course of oceanaut operation, the oceanauts need to keep their trunk leaning to observe the external environment of the submersible from the porthole; meanwhile, they are required to hold the stick for the whole operation duration. Since the low back is in the tension state, while the elbow joint is in extension, the erector spinal muscle is more prone to fatigue than other muscles.

The characteristic of muscle fatigue in men, women and different experimental participant numbers was explored according to the NRMS values displayed in Table 3. It can be seen that the difference among men between 1-participant and 3-participant experimental sets was more significant than among women. Meanwhile, compared to the 3-participant experimental set, the difference between men and women in the 1-participant set was more obvious. In addition, women tended to be more fatigued than men in the 1-participant experimental group. Finally, at the $-15^{\circ}$ porthole, the middle trapezius muscles of women were significantly more fatigued than those of men.

In summary, the iEMG and RMS values have revealed the gradual change in muscle fatigue as the task progressed in this experiment. In terms of angle design, the $+15^{\circ}$ porthole design is more conducive to lowering the muscle fatigue rate. In terms of the muscle fatigue characteristics, the change in the erector spinal muscle is more representative, and it is more prone to fatigue than the other 2 muscles.

\section{Discussion on MF and MPF}

The results of MF and MPF both indicated that the 21-minute experiment of observing the porthole at $+15^{\circ}$, $-5^{\circ}$, or $-15^{\circ}$ led to the muscle fatigue in the trapezius medius, the lower trapezius and the erector spinal muscle. It can be seen that, at the later stage of work, muscles are less fatigued at the $+15^{\circ}$ porthole, compared to the $-5^{\circ}$ and $-15^{\circ}$ portholes, as shown in Figure 6.

The MPF value of each muscle is positively correlated with other muscles at all portholes ( $\mathrm{r}>0.9$ ), which confirmed that the 3 muscles selected had the same fatigue pattern in the participants' forward-leaning posture. 
Table 9. Results of the average subjective scores in 8 body regions during the experiment conducted in the Northwestern Polytechnical University, Xi'an, China, in July-September 2019

\begin{tabular}{|c|c|c|c|c|c|c|c|c|c|c|c|c|}
\hline \multirow{3}{*}{$\begin{array}{l}\text { Body } \\
\text { region }\end{array}$} & \multicolumn{12}{|c|}{ Average subjective score } \\
\hline & \multicolumn{3}{|c|}{$+15^{\circ}$} & \multirow[b]{2}{*}{ correlation $^{\mathrm{a}}$} & \multicolumn{3}{|c|}{$-5^{\circ}$} & \multirow[b]{2}{*}{ correlation $^{\mathrm{a}}$} & \multicolumn{3}{|c|}{$-15^{\circ}$} & \multirow[b]{2}{*}{ correlation } \\
\hline & $\begin{array}{l}\text { early } \\
\text { stage }\end{array}$ & $\begin{array}{l}\text { middle } \\
\text { stage }\end{array}$ & $\begin{array}{l}\text { later } \\
\text { stage }\end{array}$ & & $\begin{array}{l}\text { early } \\
\text { stage }\end{array}$ & $\begin{array}{c}\text { middle } \\
\text { stage }\end{array}$ & $\begin{array}{l}\text { later } \\
\text { stage }\end{array}$ & & $\begin{array}{l}\text { early } \\
\text { stage }\end{array}$ & $\begin{array}{l}\text { middle } \\
\text { stage }\end{array}$ & $\begin{array}{l}\text { later } \\
\text { stage }\end{array}$ & \\
\hline Neck & 2.6 & 2.25 & 2.15 & -0.952 & 2.4 & 1.67 & 1.65 & -0.877 & 2.15 & 1.75 & 1.65 & -0.945 \\
\hline Shoulder & 2.45 & 2.15 & 2 & -0.982 & 2.2 & 2 & 1.8 & $-1^{* *}$ & 2.05 & 1.7 & 1.45 & -0.995 \\
\hline Back & 2.2 & 1.85 & 1.8 & -0.918 & 2 & 1.65 & 1.55 & -0.952 & 1.95 & 1.5 & 1.3 & -0.976 \\
\hline Waist & 2.25 & 1.95 & 1.9 & -0.924 & 2.05 & 1.8 & 1.6 & $-0.998^{*}$ & 1.95 & 1.65 & 1.35 & $-1^{* *}$ \\
\hline Hip & 4.05 & 3.85 & 3.75 & -0.982 & 4 & 3.6 & 3.55 & -0.912 & 3.85 & 3.4 & 3.4 & -0.866 \\
\hline Thigh & 4.2 & 3.85 & 3.8 & -0.918 & 4 & 3.8 & 3.65 & -0.997 & 4 & 3.8 & 3.6 & $-1^{* *}$ \\
\hline Calf & 4.3 & 4.1 & 4.1 & -0.866 & 4.35 & 4.05 & 4 & -0.924 & 4.1 & 3.95 & 3.85 & -0.993 \\
\hline Ankle & 4 & 3.85 & 3.65 & -0.997 & 4 & 3.6 & 3.35 & -0.991 & 3.8 & 3.55 & 3.3 & $-1^{* *}$ \\
\hline Overall & 3.2563 & 2.9813 & 2.8938 & -0.958 & 3.1250 & 2.7713 & 2.6438 & -0.965 & 2.9813 & 2.6625 & 2.4875 & -0.986 \\
\hline
\end{tabular}

${ }^{a}$ Pearson's correlation analysis.

$* \mathrm{p}<0.05 ; * \mathrm{p}<0.01$.

The authors also considered the influence of the participants' attributes on the MF values through correlation analysis. According to the results presented in Table 4, for the greater BMI, the MF of the trapezius was lower, and the muscles were more fatigued. That is to say, a relatively shorter and thinner participant usually felt more comfortable than a taller and stronger one, which is quite consistent with the selection criteria of oceanauts. Due to the inner space in a manned submersible being quite limited, the oceanauts with greater height and weight would feel more crowded and suffer from fidgets.

\section{Subjective scale analysis}

The subjective scales of all participants (as shown in Table 6 ) were analyzed. The subjective scores of the $+15^{\circ}$ porthole at each stage of work were higher than those at the $-15^{\circ}$ and -5 portholes, i.e., the subjective comfort of the participants for the $+15^{\circ}$ porthole was higher than that for the $-15^{\circ}$ and -5 portholes. The authors also calculated the correlation between the subjective scores and time, and the average subjective score of all regions at the $+15^{\circ}$ porthole design was the most negatively correlated with time $(\mathrm{r}=$
-0.958 ) among the 3 different portholes. In this way, the decrease rate of perceived comfort at $+15^{\circ}$ was slower than at the $-5^{\circ}$ and $-15^{\circ}$ portholes. Meanwhile, comfort perception was found to drop at the fastest rate at the $-15^{\circ}$ porthole. During the experiment, the participants' subjective scores at various angles showed the lowest scores for the back and the highest scores for the calves, i.e., the participants' backs are the most fatigued and uncomfortable, and their calves are the most comfortable. This demonstrated the rationality of the experiment design.

\section{CONCLUSIONS}

The purpose of this study was to investigate the effect of the porthole longitudinal position in manned submersibles by examining oceanauts' sEMG signals under environments with constrained spaces. To improve the reliability of the results, the subjective amount of sensory fatigue and the sEMG signal real data were analyzed during experiments with multiple porthole angles where the participants' forward-leaning working posture was fixed. Considering the limitations of the experiment, the authors just got some preliminary results, as shown in the following: 
- over time, the muscles at $-5^{\circ}$ and $-15^{\circ}$ become increasingly fatigued, but the fatigue rate is not fixed, and the fatigue does not increase uniformly. However, the muscle fatigue change at $+15^{\circ}$ during the operation is not significant;

- among the 3 muscles selected in the experiment, the erector spinal muscle is more prone to fatigue than the other 2 muscles;

- the participants' attributes, such as BMI, are negatively correlated with muscles at all porthole angles, which is highly consistent with the actual situation;

- considering the characteristics of the sEMG parameters and the subjective scale, the authors suggest $\mathrm{a}+15^{\circ}$ position to help to slow down the muscle fatigue of the oceanauts;

- in subsequent studies, other issues that may affect the results of the analysis should be considered, such as the interaction between muscles, the psychological state, and the muscle condition (muscular or lack of exercise) of the subjects.

In summary, the authors recommend that portholes are designed with angles of $+15^{\circ}$ relative to the submarine's horizontal line of sight to maximize the oceanaut's operational efficiency and to optimize the working time to reduce fatigue growth. They believe that this study will be valuable for researchers in the field of layout optimization in manned submersibles.

In view of the results of this study, the authors believe that the study of the recovery from trapezius and erector spinal fatigue in narrow manned submersibles is also a potential research topic that should be given priority.

\section{REFERENCES}

1. Gao X, Ding K, Ren Y, Fu W, Ding Z, Zhao S, et al. Target deployment and retrieval using JIAOLONG manned submersible in the depth of $6600 \mathrm{~m}$ in Mariana Trench. China Ocean Eng. 2017;31(5):618-23, https://doi.org/10.1007/s13344-0170071-9.
2. Chen D, Fan Y, Li W, Wang Y, Zhang S. Human reliability prediction in deep-sea sampling process of the manned submersible. Saf Sci. 2019;112:1-8, https://doi.org/10.1016/j.ssci. 2018.10.001.

3. Fan W. Research on Fatigue Characteristics and Layout Optimization in Narrow Working Cabin dissertation. X'an: Northwestern Polytechnical University; 2016.

4. Oldenburg M, Jensen H. Needs and possibilities for ship's crews at high seas to communicate with their home. Int J Occup Med Environ Health. 2019;32(6):805-15, https://doi. org/10.13075/ijomeh.1896.01436.

5. Cui W, Liu F, Hu Z, Zhu M, Guo W, Liu C. On 7,000 m Sea Trials of the Manned Submersible Jiaolong. Mar Technol Soc J. 2013;47:67-8, https://doi.org/10.4031/MTSJ.47.1.2.

6. Zhang S, He W, Chen D, Chu J, Fan H, Duan X. Thermal comfort analysis based on PMV/PPD in cabins of manned submersibles. Build Environ. 2019;148:668-76, https://doi. org/10.1016/j.buildenv.2018.10.033.

7. Murray M, Lange B, Chreiteh SS, Olsen HB, Nornberg BR, Boyle E, et al. Neck and shoulder muscle activity and posture among helicopter pilots and crew-members during military helicopter flight. J Electromyogr Kines. 2016;27:10-7, https://doi.org/10.1016/j.jelekin.2015.12.009.

8. Zhang S, He W, Chen D, Chu J, Fan H. A dynamic human reliability assessment approach for manned submersibles using PMV-CREAM. Int J Nav Arch Ocean. 2019;11(2): 782-95, https://doi.org/10.1016/j.ijnaoe.2019.03.002.

9. Lai PL, Chiang H, Huang Q. EMG-Based Mobile Assessment System for Neck and Shoulder Fatigue. Int J Big Data Anal Health. 2017;2(2):39-50, https://doi.org/10.4018/IJBD AH.2017070103.

10. Waongenngarm P, Rajaratnam BS, Janwantanakul P. Perceived body discomfort and trunk muscle activity in three prolonged sitting postures. J Phys Ther Sci. 2015;27(7):2183-7, https://doi.org/10.1589/jpts.27.2183.

11. Goldman MD. Human Muscle Fatigue: Physiological Mechanisms CIBA Foundation Symposium 82. Br J Dis Chest. 1983;77:317, https://doi.org/10.1016/0007-0971(83)90063-3. 
12. De Luca CJ. Myoelectrical Manifestations of Localized Muscular Fatigue in Humans. Crit Rev Biomed Eng. 1984; 11(4):251-79.

13. McDonald AC, Mulla DM, Keir PJ. Using EMG Amplitude and Frequency to Calculate a Multimuscle Fatigue Score and Evaluate Global Shoulder Fatigue. Hum Factors. 2019;61(4): 526-36, https://doi.org/10.1177/0018720818794604.

14. Chowdhury SK, Nimbarte AD. Effect of fatigue on the stationarity of surface electromyography signals. Int J Ind Ergonom. 2017;61:120-5, https://doi.org/10.1016/j.ergon.2017.05.004.

15. Enoka RM, Stuart DG. Neurobiology of Muscle Fatigue. J Appl Physiol. 1992;72(5):1631-48, https://doi.org/10.1152/ jappl.1992.72.5.1631.

16. Al-Mulla MR, Sepulveda F, Colley M. A Review of NonInvasive Techniques to Detect and Predict Localised Muscle Fatigue. Sensors (Basel). 2011;11(4):3545-94, https://doi.org/ 10.3390/s110403545.

17. Piper H. Elektrophysiologie menschlicher muskeln. Berlin: Springer-Verlag; 1912. German.

18. Lindstrom L, Magnusson R, Petersen I. Muscular fatigue and action potential conduction velocity changes studied with frequency analysis of EMG signals. Electromyography. 1970;10(4):341-56.

19. Lindstrom L, Magnusson R. Interpretation of myoelectric power spectra: A model and its applications. Proc IEEE. 1977; 65(5):653-62, https://doi.org/10.1109/PROC.1977.10544.

20. Balasubramanian V, Dutt A, Rai S. Analysis of muscle fatigue in helicopter pilots. Appl Ergon. 2011;42(6):913-8, https://doi.org/10.1016/j.apergo.2011.02.008.

21. Haddad O, Mirka GA. Trunk muscle fatigue and its implications in EMG-assisted biomechanical modeling. Int J Ind Ergonom. 2013;43(5):425-9, https://doi.org/10.1016/j.ergon. 2013.08.004.

22. Thompson BJ, Stock MS, Banuelas VK. Effects of Accumulating Work Shifts on Performance-Based Fatigue Using
Multiple Strength Measurements in Day and Night Shift Nurses and Aides. Hum Factors. 2017;59(3):346-56, https:// doi.org/10.1177/0018720816677814.

23. Anand MV, Vijayakumar KCK, Mohanraj T. Evaluation of Shoulder Pain Among the Workers Involved in Ironing Process Using Surface Electromyography. J Med Imag Health In. 2020;10(1):86-92, https://doi.org/10.1166/jmihi. 2020.2846 .

24. De Luca CJ. Use of the surface EMG signal for performance evaluation of back muscles. Muscle Nerve. 1993;16(2):210-6, https://doi.org/10.1002/mus.880160216.

25. Ertl P, Kruse A, Tilp M. Detecting fatigue thresholds from electromyographic signals: A systematic review on approaches and methodologies. J Electromyogr Kines. 2016;30:216-30, https://doi.org/10.1016/j.jelekin.2016.08.002.

26. Stulen FB, De Luca CJ. Frequency parameters of the myoelectric signal as a measure of muscle conduction velocity. IEEE Trans Biomed Eng. 1981;28(7):515-23, https://doi.org/ 10.1109/TBME.1981.324738.

27. Kahl L, Hofmann UG. Comparison of algorithms to quantify muscle fatigue in upper limb muscles based on $\mathrm{sEMG}$ signals. Medical Eng Physics. 2016:1260-9, https://doi.org/ 10.1016/j.medengphy.2016.09.009.

28. De Luca CJ. The wartenweiler memorial lecture the use of surface electromyography in biomechanics. J Biomech. 1994;27 (6):724, https://doi.org/10.1016/0021-9290(94)91124-X.

29. Kroghlund C, Jorgensen K. Myo-electric fatigue manifestations revisited: power spectrum, conduction velocity, and amplitude of human elbow flexor muscles during isolated and repetitive endurance contractions at $30 \%$ maximal voluntary contraction. Eur J Appl Physiol. 1993;66(2):161-73, https://doi.org/10.1007/BF01427058.

30. Balasubramanian V, Jayaraman S. Surface EMG based muscle activity analysis for aerobic cyclist. J Bodyw Mov Ther. 2009;13(1):34-42, https://doi.org/10.1016/j.jbmt.2008.03.002.

This work is available in Open Access model and licensed under a Creative Commons Attribution-NonCommercial 3.0 Poland License - http://creativecommons.org/ licenses/by-nc/3.0/pl/deed.en. 